\title{
COMPARATIVE ANALYSIS OF INCIDENCE AND MORTALITY FROM GASTRIC CANCER AMONG THE POPULATION OF EUROPE AND UKRAINE
}

DOI: 10.36740/WLek202103206

\author{
Tetiana I. Domanchuk, Zhanetta A. Chornenka, Mariana I. Hrytsiuk \\ BUKOVINIAN STATE MEDICAL UNIVERSITY, CHERNIVTSI, UKRAINE
}

\begin{abstract}
The aim: To study the incidence and mortality from gastric cancer in Europe and Ukraine.

Materials and methods: Using statistical and medico-epidemiological methods, the analysis of the database of the National Cancer Registry of Gastric Cancer and Global cancer statistics 2018.

Results: Gastric cancer remains an important cancer worldwide and is responsible for over 1,000,000 new cases in 2018 and an estimated 783,000 deaths, making it the fifth most frequently diagnosed cancer and the third leading cause of cancer death. Among men, it is the most commonly diagnosed cancer and the leading cause of cancer death in several countries of Europe, including Ukraine. Incidence rates are markedly elevated in Central/Eastern Europe, whereas the rates in Northern Europe are generally low. In the dynamics of the last decade, the primary incidence of gastric cancer has shown a tendency to decrease, as in Ukraine, from 25.5 per 100 thousand population in 2010 to 19.5 similar cases in 2019 , which is $-23.5 \%$ visibility) and in the Chernivtsi region (on -22.3\% visibility). In Ukraine, as well as in Europe, the incidence and mortality of gastric cancer in men is 2 times higher than in women.

Conclusions: Incidence and mortality rates have declined in Europe in the past decades. Trends in the ten-year dynamics of reducing the incidence and mortality of gastric cancer in Ukraine prove the effectiveness and feasibility of introducing preventive measures at the state level in the future.
\end{abstract}

KEY WORDS: incidence, mortality, gastric cancer, survival, Europe, Ukraine

Wiad Lek. 2021;74(3 p.II):596-602

\section{INTRODUCTION}

Gastric cancer (GC) is an important contributor to the global burden of cancer, [1] and less than a century ago it was the most common cancer in the world [2]. Since then, the incidence and mortality rates of gastric cancer have fallen [3]. However, this trend has shown signs of change; for example, some researchers suggest that in the USA, the rates of gastric cancer might be increasing among younger age groups (i.e., $<50$ years) and predict that this increase might reverse the overall decline in the incidence of GC [4]. The decreasing trend of gastric cancer incidence and mortality in most populations is due to the falling in Helicobacter pylori infection rates [5]. H.pylori is a known carcinogen for non-cardia GC, which probably once infected most adults during their life course [6]. Improved socio-economic status, hygienic practices, and widespread antibiotic use have led to a decrease in infection rates. Improved socio-economic status, hygienic practices, and widespread antibiotic use have led to a decrease in infection rates.

The prevention and treatment of stomach cancer is pivotal, since it is currently one of the most common malignancies around the world. Ukraine is one of the countries with a high level of cancer and is among the top ten countries in the world in this regard. Moreover, according to scientists, by 2020 the number of people who get cancer for the first time in Ukraine will exceed 200 thousand people [7]. This emphasizes the importance of prevention of malignant neoplasms. Important indicators of the effectiveness of this area of the health care system are the levels and trends of morbidity and mortality, including early detection and survival of cancer patients [8]. Ukraine ranks 8-9 in the list of 49 countries with registered cancer (incidence of men -39.5 per 100 thousand population, women -22.4), annually the country registers 16-17 thousand new cases.

GC occupies one of the leading positions in the structure of morbidity and mortality. It is one of the most common human tumours and ranks 2 nd in the structure of cancer. In economically developed countries, the proportion of GC reaches $50 \%$ of all tumours of the gastrointestinal tract and $10-15 \%$ of the total number of tumours [9]. Every year, 750-850 thousand new cases of GC are registered in the world and more than 600 thousand people die from this disease, despite the stabilization of the incidence in some developed countries [10].

GC is currently the fifth most common cancer and the third leading cause of cancer death in the world [11]. In 2018, the global incidence of GC was 12.1 / 100,000 [11]. The total number of newly diagnosed cases of GC was estimated at 952,000 , which is $6.8 \%$ of all newly detected malignancies and is $8.8 \%$ of cancer-related deaths [11]. The incidence of GC is approximately twice as common in men 


\section{Morbidity and mortality from GC}

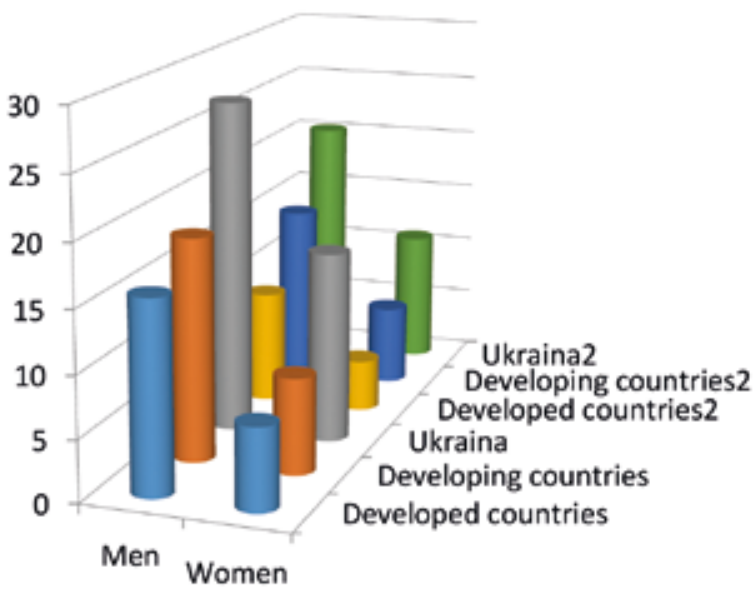

= Developed countries

n Developing countries

E Ukraina

= Developed countries2

neveloping countries2

n Ukraina2
Fig.1. Comparative assessment of morbidity and mortality (2) from GC among men and women in developed countries, developing countries and Ukraine. as in women, most cases occur after 60 years $[12,13]$. Despite declining morbidity, gastric cancer still has a gloomy, $20 \%, 5$-year survival rate $[14,15]$ and a high mortality rate in $74.5 \%$ in most countries [16]. Gastric cancer is a major factor influencing disability-adjusted life expectancy and early cancer mortality and has a significant impact on overall health and life expectancy worldwide [17].

According to the Cancer Registry of Ukraine, in 2018, the GC ranks fourth in morbidity (6.9\%) and second in mortality (9.5\%) from malignant neoplasms in men, second only to lung and prostate cancer. The incidence of gastric cancer in women is in seventh place $(4.1 \%$ among all malignant tumours), and mortality is in third place $(7.5 \%$ among all malignant tumours) after breast and colon cancer [7].

Morbidity and mortality can be considered as indicators of the level of socio-economic development of the state in general and the public health system in particular. After all, in the scientific literature it is proved that in the occurrence of pathology a significant role is played by general risk factors, such as: stress, poverty, unhealthy lifestyle, unsatisfactory social conditions, anthropogenic pollution, harmful working conditions, etc. [7, 9], so and special: smoking, alcohol and hot or too cold food and drink, chronic trauma, papillomavirus infection, and precancerous diseases [18]. Most of these factors are manageable and can be moderated through the organized efforts of society as a whole, i.e. they depend on the effectiveness of the public health system.

\section{THE AIM}

The aim is to study the ten-year trends in morbidity and mortality due to malignant neoplasms of the stomach in Europe and Ukraine (including Chernivtsi region).

\section{MATERIALS AND METHODS}

Analyzed the database of the National Cancer Registry of Ukraine for 2010-2019 [7] and Global cancer statistics 2018 [9]. Used methods: epidemiological, medical and statistical.

\section{RESULTS}

There are significant regional differences in current GC incidence and mortality. The highest rates are observed in East Asia, Eastern and Central Europe and South and Central America. Gastric cancer rates are also significantly lower in more economically developed regions of the world than in less developed ones (age-standardized incidence rate [ASIR] per 100,000: men = 15.6 vs. 18.1 ; ASIR women $=6.7$ vs. 7.8 Age-standardized mortality rate [ASMR] per 100,000: men $=9.2$ vs. 14.4 ; ASMR women 4.2 vs. 6.5) [9] . More developed countries, as defined by the UN, include all regions of Europe plus North America, Australia / New Zealand and Japan; less developed countries include all regions of Africa, Asia (except Japan), Latin America and the Caribbean, Melanesia, Micronesia and Polynesia (Fig.1). More than 70\% of GC occurs in less developed countries.

As can be seen from the graph, both morbidity and mortality rates compared to European countries in Ukraine are much higher - for both men and women.

Central / Eastern Europe has the second highest rate of GC after East Asia, with an estimated ASIR of 13.5 / 100,000 and an ASMR of 10.9 / 100,000. Western Europe and Northern Europe have medium levels of gastric cancer (ASIR: 6.3 and 5.4 per 100,000, respectively). The main indicators of morbidity, mortality and survival in Europe and Ukraine, as of 2018 are presented in Table I.

Research in recent year's shows that incidence rates in most industrialized countries have declined and patterns emerging in immigrant groups move toward patterns in origin countries. These changes indicate that a close relationship gastric cancer with factors can be altered. Economic growth and life style changes are following by unhealthy nutritious diets, lack of physical activity, overweighting and obesity which are all the cancer risk factors and the reasons of increasing general health concern. On the other hand, the treatment and recovery methods including increasing of physical activity, healthy food consumption, and the proper screening can affect reducing deaths. The rate of infection-inducing cancer prevalence and deaths 
Table I. Incidence, mortality and survival rates in Europe and Ukraine in 2018

\begin{tabular}{|c|c|c|c|c|}
\hline European countries & $\begin{array}{l}\text { New cases } \\
\text { per } 100 \text { thousand } \\
\text { population }\end{array}$ & $\begin{array}{l}\text { Mortality } \\
\text { per } 100 \text { thousand } \\
\text { population }\end{array}$ & Incidence & Survival \\
\hline Austria & 1190 & 806 & 13,1 & 35,4 \\
\hline Belarus & 2885 & 1723 & 30,5 & - \\
\hline Belgium & 1577 & 788 & 13,8 & 37,5 \\
\hline Bulgaria & 1318 & 1066 & 17,6 & 16 \\
\hline Croatia & 865 & 763 & 20,0 & 20,0 \\
\hline Czech Republic & 1399 & 987 & 13,6 & 20,6 \\
\hline Denmark & 543 & 406 & 9,5 & 19,9 \\
\hline Estonia & 328 & 275 & 24,6 & 29,2 \\
\hline Finland & 585 & 429 & 10,0 & 25,7 \\
\hline France & 7726 & 5326 & 11,5 & 26,7 \\
\hline Georgia & 651 & 520 & 16,7 & - \\
\hline Germany & 14773 & 9480 & 15,1 & 33,5 \\
\hline Greece & 1908 & 1423 & 15,7 & - \\
\hline Hungary & 2089 & 1523 & 22,1 & - \\
\hline Iceland & 27 & 21 & 8,0 & 28,1 \\
\hline Italy & 12803 & 9457 & 17,8 & 30,5 \\
\hline Latvia & 564 & 448 & 28,0 & 28,0 \\
\hline Lithuania & 869 & 722 & 29,5 & 27,0 \\
\hline Netherlands & 1833 & 1341 & 10,9 & 25,0 \\
\hline Norway & 472 & 318 & 10,0 & 26,5 \\
\hline Poland & 6659 & 5779 & 18,9 & 20,9 \\
\hline Portugal & 2885 & 2275 & 25,0 & 32,2 \\
\hline Romania & 3530 & 3923 & 18,8 & 26,5 \\
\hline Russia & 35213 & 29565 & 24,5 & 21,0 \\
\hline Slovenia & 452 & 313 & 21,0 & 28,8 \\
\hline Spain & 7684 & 5609 & 15,6 & 27,6 \\
\hline Sweden & 776 & 557 & 7,7 & 24,8 \\
\hline Switzerland & 1017 & 636 & 12,1 & 32,2 \\
\hline UK & 6370 & 4484 & 9,9 & 20,7 \\
\hline Ukraine & 9417 & 8307 & 21,4 & 15,9 \\
\hline
\end{tabular}

would contribute to high costs among the majority of the countries. Infection-related cancers contain more than $26 \%$ of all cancers among low-income and middle-income countries while the rate of non-infectious cancers is increasing in all countries except for level of income. This desired increase is an indicative of higher prevalence of known risk factors such as obesity, lack of physical activity and smoking as well as higher usage of screening methods.

Evaluating these tables - the highest 5-year survival rates are observed in Austria, Belgium, Germany, Portugal and Switzerland - countries with high socio-economic living standards. Post-Soviet countries such as Belarus, Georgia, Hungary, Kazakhstan, Uzbekistan and others do not calculate this figure still. In Ukraine, the survival rate of various cancer sites began to be calculated only in the last few years.
GC has a poor prognosis. The EUROCARE- 5 survey, which estimates survival in Europe since 1999, reports a European relative survival over 5 years of $25 \%$, the best in Southern Europe is close to 30\%, and the worst in Eastern Europe is 19\%.

According to the results of cancer records in 2018, [9] 133133 cases of GC were recorded among all European countries for both sexes. The highest incidence of GC 64482 cases $(48.4 \%)$ was associated with Central / Eastern Europe, and the lowest - 11244 cases (8.4\%) - with Northern Europe. The incidence of GC in Ukraine (7492 new cases) as well as in European countries shows a tendency to decrease over the last decade from 25.5 per 100 thousand population in 2010 to 19.5 similar cases in 2019, which corresponds to intermediate level. Also in our study, for comparison, we evaluated the incidence and mortality of GC in the 


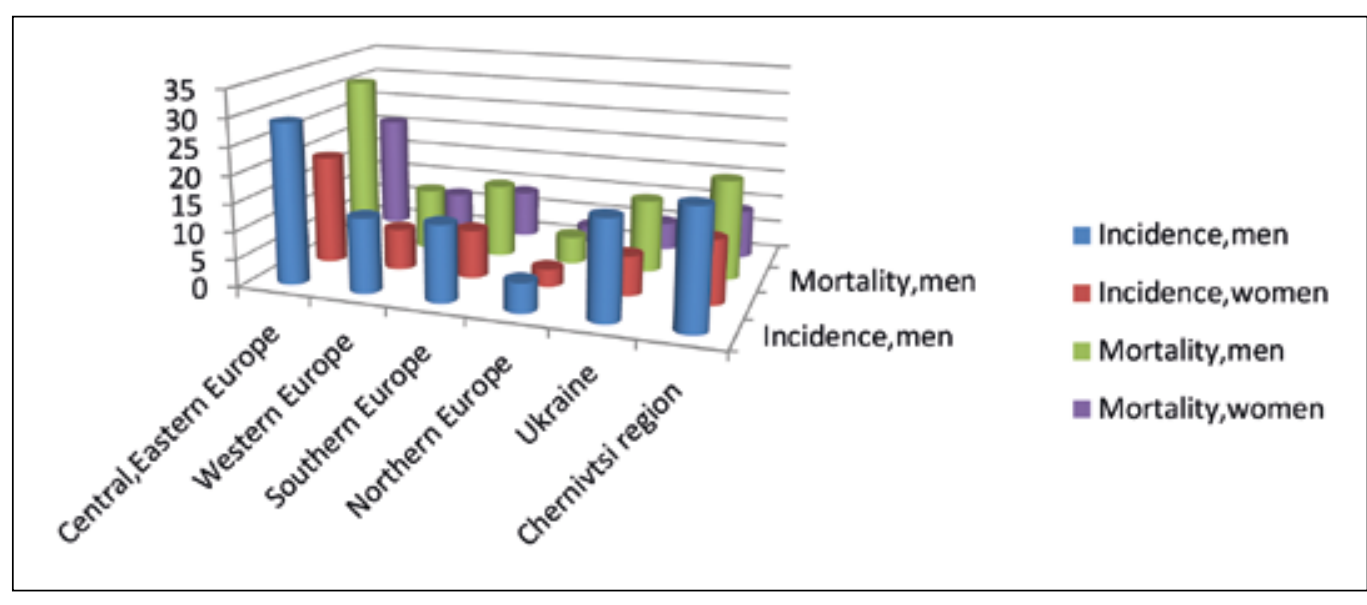

Fig.2. Incidence and mortality of gastric cancer among the population of Europe and Ukraine (per 100,000)

Table II. Survival of patients with malignant neoplasms of the stomach

\begin{tabular}{|c|c|c|c|c|c|c|c|c|c|c|}
\hline \multirow{3}{*}{$\begin{array}{l}\text { Administrative } \\
\text { region }\end{array}$} & \multirow{3}{*}{$\begin{array}{c}\begin{array}{c}\text { Number of } \\
\text { patients, } \mathbf{n}\end{array} \\
\text { m }\end{array}$} & \multicolumn{6}{|c|}{ 1-year survival } & \multirow{2}{*}{\multicolumn{2}{|c|}{$\begin{array}{c}\text { 5-year survival } \\
\text { Lost from supervision, } \%\end{array}$}} & \multirow[b]{3}{*}{ w } \\
\hline & & \multicolumn{2}{|c|}{ Survival, $\%$} & \multicolumn{2}{|c|}{ Lost from supervision, $\%$} & \multicolumn{2}{|c|}{ Survival, $\%$} & & & \\
\hline & & w & m & w & m & w & m & w & m & \\
\hline Ukraine & 30103 & 19768 & $34,8 \pm 0,4$ & $36,7 \pm 0,5$ & 2,5 & 3,3 & $14,8 \pm 0,4$ & $16,9 \pm 0,5$ & 5,2 & 6,6 \\
\hline Chernivtsi region & 547 & 336 & $37,4 \pm 2,4$ & $40,9 \pm 2,9$ & 1,5 & 1,5 & $14,2 \pm 2,0$ & $20,3 \pm 2,6$ & 3,6 & 5,5 \\
\hline
\end{tabular}

least region of Ukraine, namely Chernivtsi. Thus, in the Chernivtsi region, the incidence of GC decreased from 20.6 in 2010 to 16.0 in 2019 per 100 thousand population, respectively (Fig.2).

In our opinion, an important reason for such positive dynamics may be: promotion of a healthy lifestyle, smoking cessation and alcohol use at the state level (Ukraine's accession to the WHO Framework Convention on Tobacco Control and the implementation of a number of appropriate preventive measures at the state level [8]), modern possibilities of endoscopy and biopsy performed among the population at risk to assess the course of various diseases and precancerous conditions, which significantly increases the likelihood of early detection of GC and improves treatment outcomes.

The total number of deaths from gastric cancer in 2018 among all European countries was 102167 cases, indicating the second place of death due to GC, after lung cancer. The highest mortality rate, as well as morbidity, was observed in Central / Eastern Europe 54268 cases (53.1\%), and the lowest mortality rate was in Northern Europe with 8014 cases (7.8\%). Mortality from GC in Ukraine also decreased slightly from 19.2 to 14.0 per 100 thousand population during 2010-2019 (which is - 27\% in terms of visibility). Similar to the incidence rates, gastric mortality rates in Chernivtsi region are also not significantly lower than similar rates for GC in Ukraine and showed approximately the same trends as in the primary incidence over the past ten years, fluctuated with varying intensity in the range of 18.3-13.2 cases per 100 thousand population, which is $27.9 \%$ showing a generally stable trend and equalization of indicators over the past five years to national values.

It should be noted that men suffer from GC several times more often than women (Fig.2).
No clear etiological factors for the occurrence of GC have been identified, although it is known that some conditions contribute to the development of gastric cancer. The role of nutrition is important: an unfavourable role is played by carbohydrate foods, lack of vitamins, especially vitamin A, ascorbic acid. Higher incidence of gastric cancer is observed in areas with excessive levels of nitrates in soil, water and food (Kyiv 23.6, Kharkiv 24.5, Khmelnytsky 25.0 and Chernihiv region 30.3 per 100 thousand population). Nitrates during interaction with amines in the stomach, especially with low acidity of gastric juice, form nitrosamines, the carcinogenic effect of which has been proven. Bacteria that promote the synthesis of nitrosamines die in the normal environment of the stomach. Foods high in benzopyrene (smoked, fried foods) also cause GC, which predominate in the diet of older men. Increased morbidity and mortality from gastric cancer among the male population of Ukraine can also be explained by the abuse of strong alcoholic beverages, smoking. Among smokers, the risk of the disease is four times higher than among non-smokers. Consumption of salty foods increases the risk of disease several times, and consumption of milk (as well as fresh vegetables and fruits) reduces the risk of disease by $30 \%$. The disease is facilitated by a lack of cobalt, magnesium in the soil and food, an excess of zinc and copper. Vitamin A, carotene, synthetic retinoid, ascorbic acid, which have antioxidant properties, prevent the formation of nitrosamines in the digestive tract.

Also, one of the most adequate criteria for assessing the effectiveness of cancer care is survival. It should be noted that the study of this indicator at the population level in different countries is quite rare. The first international cancer survival studies were conducted in 1964 by the US National Cancer Institute and included patients from 
Denmark, England, Finland, France, Norway and the United States with the most common nosological forms of cancer. Subsequently, such studies were conducted by the International Agency for Research on Cancer, using data from population cancer registries in some countries, provided that they meet quality standards and the level of traceability of patients, which should be $95 \%$ for statistical reliability. In Ukraine, population survival has not been studied in cancer epidemiological research; as a rule, the survival rate is used only for comparative evaluation of the effectiveness of different treatments in clinical trials.

Survival analysis in Ukraine was performed for patients with GC (C16) diagnosed in 2014-2019, except for patients with multiple tumours; the studied cohort included 23,991 men and 15,589 women. The values of relative survival by cumulative method for male and female population of both Ukraine in general and in Chernivtsi region in particular were calculated. The study uses personalized data from the National Cancer Registry of Ukraine and modern methods of statistical analysis adopted in oncology and descriptive epidemiology. Based on the principles and methods of medical informatics, quality control of primary information in the database was carried out.

The survival rate of patients with gastric cancer was studied in a cohort of 30,103 men and 19,768 women (Table 2) and compared with a similar incidence of cancer in the Chernivtsi region. It was found that the 1-year survival rate in Chernivtsi region among men and women of this cohort is significantly higher than the average Ukrainian $(39,2 \mathrm{i}$ $35,8 \%$ respectively). The difference in the 5 -year survival of patients with malignant neoplasms of the stomach in men and women in Chernivtsi region in comparison with the average in Ukraine (16,1 i 15,9\%) was not so significant.

The 5-year survival rate of patients with gastric cancer in the regions we studied is $2-2.5$ times lower than the 1 -year level. To find out the possible reasons for the low survival rate of patients with gastric cancer, the main indicators of the organization of cancer care for patients in this category were studied. It was found that in the Chernivtsi region the level of detection of gastric cancer in the abandoned stage is 1.2 times higher than in the all-Ukrainian.

The 1-year survival of this category of patients is almost 1.6 times less than the rate of detection of the disease in the I-II stage in Chernivtsi region and almost coincides with the corresponding indicators in Ukraine. In Chernivtsi region, $14.3 \%$ fewer patients survive within 1 year than were detected in stages I - II, which indicates a possible inadequacy of establishing the stage of the disease. It was also revealed that in Chernivtsi region half of patients with gastric cancer were covered by special treatment, and in Ukraine - $45.1 \%$.

It is also important to analyse indicators of the quality of preventive work of medical institutions, which include indicators of neglect (detection of MN at stage III-IV and mortality up to a year from diagnosis), as well as the proportion of primary cases detected during preventive examinations. Correlation-regression analysis proved that there is a strong feedback between the last indicator and the indicators of neglect: the higher the coverage of preventive examinations, the lower the frequency of late stages of cancer ( $\mathrm{rxy}=-0.97, \mathrm{p}<0.05)$ and mortality up to one year $(-0.99)$. However, there is a strong direct relationship between the two indicators of neglect (0.98). In this regard, the best situation and dynamics are characteristic of indicators of early diagnosis of gastric cancer.

During the study period, only a small proportion of primary cases in Ukraine were detected during preventive examinations $(9.3 \%$ and $6.6 \%$ in 2010 and 2019 , respectively), which indicates an insufficient level of preventive work with the population. As the rates of neglect are quite high and do not show a positive trend in both late detection $(30.8 \%$ and $36.5 \%)$ and mortality up to one year $(62.2 \%$ and $59.7 \%)$, there is a need for in-depth study of medical -organizational causes of late detection of gastric cancer as a scientific basis for the development of effective prevention measures.

\section{DISCUSSION}

This article summarizes the epidemiological aspects of GC at the present stage in the global health care of European countries and Ukraine. An analysis of recent trends in GC morbidity and mortality has shown that there is a relatively permanent and steady decline in these rates in most other parts of the world, particularly in Europe. Worldwide, GC is more common in men than women (1.5-2.5: 1) [19]. The proportion of GC in the male population is $9.7 \%$ (4th place), in the female $-5.8 \%$ (5th place) [20]. In Japan, with a population of about 126 million, the incidence in men is 77.9 and in women -33.3 per 100 thousand population [21]. To date, despite all advances in medicine, except Korea and Japan, where systematic screening programs are widely implemented, about $2 / 3$ of patients with GC in the world are in the early stages [22]. According to studies in the United States [23] showed that about $60 \%$ of patients at the time of diagnosis had stage III or IV disease, and researchers in the Netherlands noted that from the early 90 's to the present there has been an increase in the detection of stage IV cancer from $31 \%$ to $40 \%$, such data are indicated by other authors [22]. At the same time, the literature presents data on the increase in early detection of GC in patients in many countries: from 14.5 to $20.8 \%$ - in Portugal, $14 \%$ - in Japan, 16-20\% - in Germany, 40- 60\% - in Poland, 9\% - in the US and only $1 \%$ of patients - in the UK [23].

Despite declining incidence and mortality from GC worldwide in recent decades, mortality has declined slightly [23]. Over the past 10 years, mortality, in contrast to the incidence of GC, tends to increase due to an increase in the proportion of patients with stage IV [24]. In the world, the highest survival rate is registered in Japan - 53\% [25], in other countries it does not exceed $15-20 \%$ [26]. It should be noted that the share of early GC in Japan is the largest and accounts for half of all cases, while in Europe, the United States and other countries it does not exceed $20 \%$. In this regard, there have been suggestions that the GC in the Japanese is fundamentally different from the GC in the Europeans, but further research 
in molecular biology has shown that this assumption is wrong, and progress in improving survival in Japan is due to adopted national programs to combat cancer and mass screening of the population. Decreases in morbidity and mortality have been observed in countries with very low rates, such as Sweden or Switzerland in Europe, the United States and Australia, and this has been particularly marked among young people, indicating that declining trends are likely to continue in the future.

As mortality from GC has long been declining, the absolute decline is now smaller and will be even smaller in the future. During the 1990s, GC, along with colorectal and lung cancer, was a major contributor to the decline in overall cancer mortality in Europe, with more than 30,000 deaths avoided each year since the late 1980s in 15 EU countries (defined as before 20045, [27]). In the same countries, the absolute decline corresponds to less than 20,000 deaths, which were avoided per year in the last years, due to lower mortality rates.

Among women aged 30-49, gastric cancer mortality has stopped declining in several European countries, including France, the United Kingdom and Australia, at around $1 /$ 100,000 , in contrast to Ukraine. However, there were several parts of the world, including not only East Asia and South America, but most of Central and Eastern Europe $[28,29]$, where higher rates of gastric cancer morbidity and mortality were still observed.

The stability of trends for any age and the reduction in the age of 35-64 years is an additional indicator of the reliability of the death certificate from GC. In any case, it is unlikely that any change in the diagnosis and certification of GC explains more than a small fraction of the widespread and significant trends in GC mortality observed in recent decades. [30, 31]

The reasons for the overall decline in GC are complex and not fully understood. It almost certainly includes a more varied and rich diet and better food preservation, including refrigeration, as well as control of $\mathrm{H}$. pylori infection.

In conclusion, despite encouraging mortality trends, GC remains one of the leading causes of death worldwide, but is likely to decline further. Primary dietary prevention of gastric cancer is possible by encouraging high-risk populations to reduce the consumption of dried meat and foods stored in salt and increase the consumption of fruits and vegetables. $[32,33]$ Prevention may also be possible by eliminating $\mathrm{H}$. pylori infection, especially in children and adolescents.

\section{CONCLUSIONS}

GC incidence has declined throughout the world largely as a consequence of economic improvements that have brought about improved food preservation, availability, improved sanitation, access to clean water, and improved household hygiene which further led to a fall in $\mathrm{H}$. pylori acquisition and a decline in prevalence among subsequent generations. The epidemiological situation with gastric cancer remains threatening and is characterized by an increase in the primary incidence of the population of Ukraine, in half of the cases due to neglected stages. This leads to low survival (over $40 \%$ die within a year) and increased mortality, mainly male.

The results indicate the urgent need to develop and implement a program for the prevention of gastric cancer at the state and regional levels.

\section{REFERENCES}

1. Van Cutsem E., Sagaert X., Topal B. et al. Gastric cancer. Lancet. 2016; 388:2654-64.

2. Karimi P., Islami F., Anandasabapathy S. et al. Gastric cancer: descriptive epidemiology, risk factors, screening, and prevention. Cancer Epidemiol Biomarkers Prev. 2014; 23: 700-13.

3. Luo G., Zhang Y., Guo P. et al. Global patterns and trends in stomach cancer incidence: Age, period and birth cohort analysis. Int J Cancer. 2017; 141: 1333-44.

4. Anderson W.F., Rabkin C.S., Turner N. et al. The changing face of noncardia gastric cancer incidence among US non-Hispanic Whites. J Natl Cancer Inst. 2018; 110: 608-15.

5. Herrera V., Parsonnet J. Helicobacter pylori and gastric adenocarcinoma. Clin Microbiol Infect. 2009; 15: 971-76.

6. Rothenbacher D., Bode G., Berg G. et al. Helicobacter pylori among preschool children and their parents: evidence of parent-child transmission. J Infect Dis. 1999; 179: 398-402.

7. National Cancer Registry of Ukraine: short description of the database. Cancer in Ukraine. Ukrainian cancer registry statistics, bulletin of national cancer registry of Ukraine - № 12-21. [Elektronnyiy resurs]. http://www.ncru.inf.ua/publications/index.htm. (In Ukrainian).

8. Dumansjkyj Ju.V., Severyn Gh.K. Dorichna letaljnistj khvorykh na zlojakisni novoutvorennja. Visnyk socialjnoji ghighijeny i orghanizaciji okhorony zdorov'ja Ukrajiny. [Annual mortality of patients with malignant neoplasms]. Bulletin of social hygiene and health care organization of Ukraine. 2014; 1(59):59-64. (In Ukrainian).

9. Ferlay J., Colombet M., Soerjomataram I. et al. Global and Regional Estimates of the Incidence and Mortality for 38 Cancers: GLOBOCAN 2018. Lyon: International Agency for Research on Cancer. World Health Organization. 2018.

10. Global Cancer Facts and Figures. 2nd Edition WHO. American Cancer Society. 2011:60 . http://www.cancer.org/acs/groups/ content/\%40epidemiologysurveilance/documents/document/ acspc-027766.pdf.

11. Torre L.A., Bray F., Siegel R.L. et al. Global cancer statistics, 2012. CA Cancer J Clin. 2015;65(2):87-108. doi:10.3322/caac.21262.

12. Ferlay J., Soerjomataram I., Ervik M. et al. GLOBOCAN 2012 v1.0, Cancer incidence and mortality worldwide: IARC CancerBase No. 11. Lyon, France: International Agency for Research on Cancer. 2013.

13. Marques-Lespier J.M., Gonzalez-Pons M., Cruz-Correa M. Current perspectives on gastric cancer. Gastroenterol Clin N Am. 2016;45(3):41328. doi:10.1016/j.gtc.2016.04.002.

14. Lui F.H., Tuan B., Swenson S.L., Wong R.J. Ethnic disparities in gastric cancer incidence and survival in the USA: an updated analysis of 1992-2009 SEER data. Dig Dis Sci. 2014;59(12):3027-34. doi:10.1007/ s10620-014-3275-3.

15. Karimi P., Islami F., Anandasabapathy S. et al. Gastric cancer: descriptive epidemiology, risk factors, screening, and prevention. Cancer epidemiology, biomarkers \& prevention: a publication of the American Association for Cancer Research, cosponsored by the American Society of Preventive Oncology. 2014;23(5):700-13. doi:10.1158/1055-9965. epi-13-1057. 
16. Fock K.M. Review article: the epidemiology and prevention of gastric cancer. Aliment Pharmacol Ther. 2014;40(3):250-60. doi: 10.1111/ apt.12814.

17. Soerjomataram I., Lortet-Tieulent J., Parkin D.M. et al. Global burden of cancer in 2008: a systematic analysis of disability-adjusted life-years in 12 world regions. Lancet. 2012;380(9856):1840-50. doi:10.1016/ s0140-6736(12)60919-2.

18. Merabishvili V.M. Rak zheludka: epidemiologiya, profilaktika, otsenka effektivnosti lecheniya na populyatsionnom urovne. Prakt onkologiya [Stomach cancer: epidemiology, prevention, assessment of the effectiveness of treatment at the population level]. Practice oncology. 2001;7(3):3-8. (In Russian).

The work is a fragment of the research project of the department of social medicine and public health (Bukovinian State Medical University) «Substantiation and development of medical and social technologies for the prevention of major non-infection diseases» (2020-2024, State Registration 0120U102625).

\section{ORCID and contributionship:}

Tetiana I. Domanchuk: 0000-0003-1244-8702 B,C,D

Zhanetta A. Chornenka: 0000-0003-2314-1976 ${ }^{A, F}$

Mariana I. Hrytsiuk: 0000-0003-1000-6417 ${ }^{\text {,F }}$

\section{Conflict of interest:}

The Authors declare no conflict of interest.

\section{CORRESPONDING AUTHOR}

Zhanetta A. Chornenka

Bukovinian State Medical University

2 Teatralnaya Square, 58002 Chernivtsi, Ukraine

tel:(050)5606077

e-mail: zhanetta.chornenka.80@gmail.com

Received: 10.10 .2020

Accepted: 05.03.2021

A - Work concept and design, B - Data collection and analysis, C - Responsibility for statistical analysis,

D-Writing the article, $\mathbf{E}$-Critical review, $\mathbf{F}$ - Final approval of the article 